\title{
Medico-Legal Forum Case Debrief: Mitchell v. Shikora et al.
}

\section{Jon Fanaroff, MD, JD, Gilbert I. Martin, MD}

Procedures can be one of the most gratifying aspects of neonatology. In cases such as intubation, ECMO, or pericardiocentesis, they are lifesaving. Some procedures, such as blood draws, occur multiple times a day in every NICU. All procedures carry risks, and adverse events may occur even though everything was done correctly. While such situations are unfortunate, they are not considered to be medical malpractice. In Pennsylvania, however, a dispute arose over whether juries were entitled to hear about known complications of a procedure. The case, Mitchell v. Shikora et al., ultimately went to the Supreme Court of Pennsylvania. While it involved surgery on an adult, the principles would equally apply in the NICU.

\section{"In Pennsylvania, however, a dispute arose over whether juries were entitled to hear about known complications of a procedure. The case, Mitchell v. Shikora et al., ultimately went to the Supreme Court of Pennsylvania. While it involved surgery on an adult, the principles would equally apply in the NICU."}

\section{Facts:}

Gynecologist Dr. Shikora, assisted by a resident, was set to perform a laparoscopic hysterectomy on Lanette Mitchell in May 2016. Laparoscopic operations are performed using instruments and a camera inserted through small (less than a centimeter) incisions. Benefits include less pain and faster healing and recovery. However, before the camera can be inserted, the surgeon must obtain access to the peritoneal cavity, and there can be damage to abdominal organs. Indeed, one study of complications during laparoscopic gynecological cases found that $57 \%$ occurred while accessing the abdominal cavity. Unfortunately, this is what occurred to Ms. Mitchell. During initial entry into the peritoneal cavity, her bowel was perforated, and a general surgeon was called in to repair the bowel. For a period, there was an ileostomy pouch.

\section{The Lawsuit}

Six months after the surgery, Ms. Mitchell filed a medical malpractice lawsuit against Dr.Shikora and the hospital for "failing to take reasonable precautions to prevent [Mitchell] from suffering complications, injuries and/or damages in connection with the surgery. "For the trial, the plaintiffs asked the judge to prevent the defense from introducing evidence concerning the procedure's risks as being irrelevant, unfairly prejudicial, or confusing. The judge disagreed, and the defense was allowed to present the reasons why a complication can occur even when everything is done correctly. Dr. Shikora testified that bowel perforation is a known complication of laparoscopic surgery since the initial entry into the abdominal cavity is "blind." The expert for the defense noted that Dr. Shikora and the resident met the standard of care during the surgery and that the injury, in this case, was unavoidable and occurred even without negligence since a physician cannot see what is behind the peritoneum. The jury found for the defense, and the plaintiffs appealed.

\section{Superior Court Opinion}

A panel of the Superior Court agreed with the plaintiffs, nullified the jury verdict, and ordered a new trial. They felt that the defense should not have been allowed to discuss the risks and complications of the surgery as being "irrelevant, misleading and confusing." In particular, they were concerned that evidence of known complications "would tend to mislead and/or confuse the jury by leading it to believe that [Mitchell's] injuries were simply the result of the risks and complications of the surgery." The defendants appealed this decision, and the Supreme Court of Pennsylvania accepted the case.

\section{Supreme Court of Pennsylvania}

The Supreme Court of Pennsylvania reversed the Superior Court decision and found that "evidence of risks and complications of a surgery may be admissible at trial." The Court recognized that

risks and complications evidence may assist the jury in determining whether the harm suffered was more or less likely to be the result of negligence. Therefore, it may aid the jury in determining both the standard of care and whether the physician's conduct deviated from the standard of care.

With this decision, the jury verdict was reinstated, and the defense prevailed in the lawsuit.

\section{"While this is not the type of case that generates headlines, it is the type of case that would have tremendous implications for neonatologists. Imagine trying to defend an adverse outcome after a procedure without discussing the known risks and complications of that procedure!"}

\section{Discussion}

While this is not the type of case that generates headlines, it is the type of case that would have tremendous implications for neonatologists. Imagine trying to defend an adverse outcome after a procedure without discussing the known risks and complications of that procedure! Just as with laparoscopic surgery, procedures in the NICU such as chest tube insertion and emergent pericardiocentesis are also "blind" and subject to similar complications. 
Medical malpractice generally requires the plaintiff to show that the physician was negligent, but if the Superior Court decision remained the law, physicians would end up more in the position of a guarantor, liable anytime a complication occurred regardless of whether that complication was avoidable.

\section{References:}

1. Henry, TA. Pennsylvania physicians could face more medical negligence cases. American Medical Association. https:// www.ama-assn.org/practice-management/sustainability/pennsylvania-physicians-could-face-more-medical-negligence-cases. Accessed 7/3/2021.

2. Mitchell v. Shikora, 161 A.3d 970 (Pa. Super. 2017)

3. Mitchell v. Shikora, J-77-2018, (Pa. Jun. 18, 2019)

4. Perugini RA, Callery MP. Complications of laparoscopic surgery. In: Holzheimer RG, Mannick JA, editors. Surgical Treatment: Evidence-Based and Problem-Oriented. Munich: Zuckschwerdt; 2001.

Disclosure: There are no reported conflicts.

NT

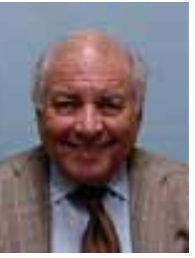

Corresponding Author

Gilbert I Martin, MD, FAAP

Division of Neonatal Medicine

Department of Pediatrics

Professor of Pediatrics

Loma Linda University School of Medicine

Email: gimartin@llu.edu

Office Phone: 909-558-7448

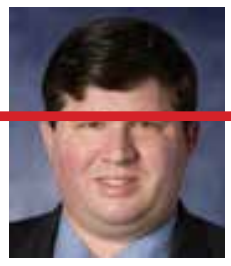

Jonathan Fanaroff, MD, JD, FAAP

Professor of Pediatrics

Case Western Reserve University School of Medicine

Director, Rainbow Center for Pediatric Ethics

Rainbow Babies \& Children's Hospital

Cleveland, Ohio

Email: imf20@case.edu

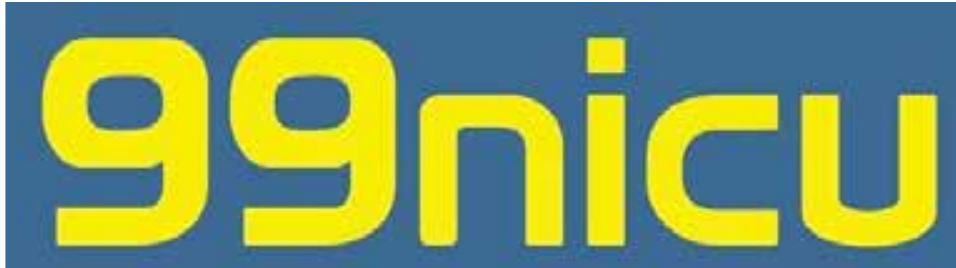

\section{Oo National Perinatal Association PERINATAL MENTAL HEALTH}

nationalperinatal.org/position

www.nationalperinatal.org/mental_health

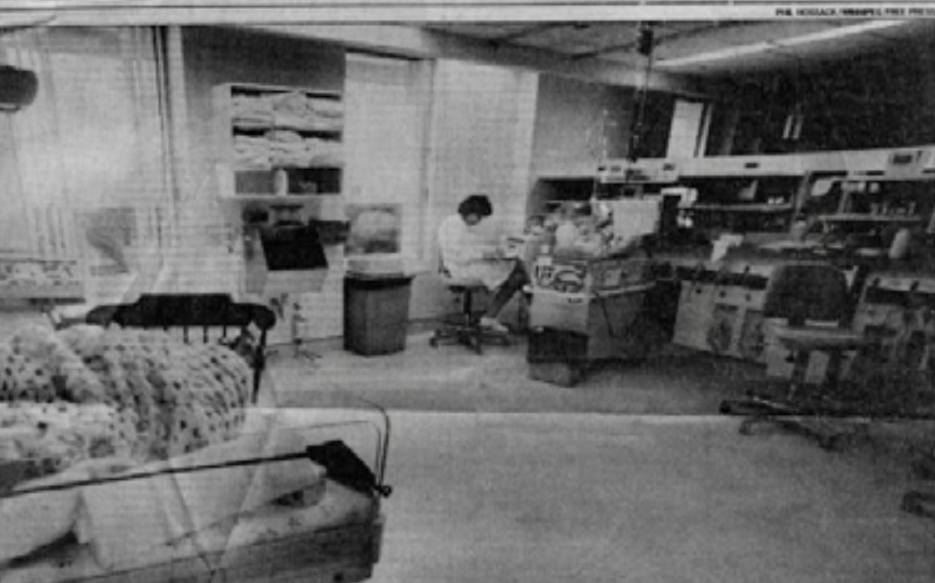

Educate. Advocate. Integrate.

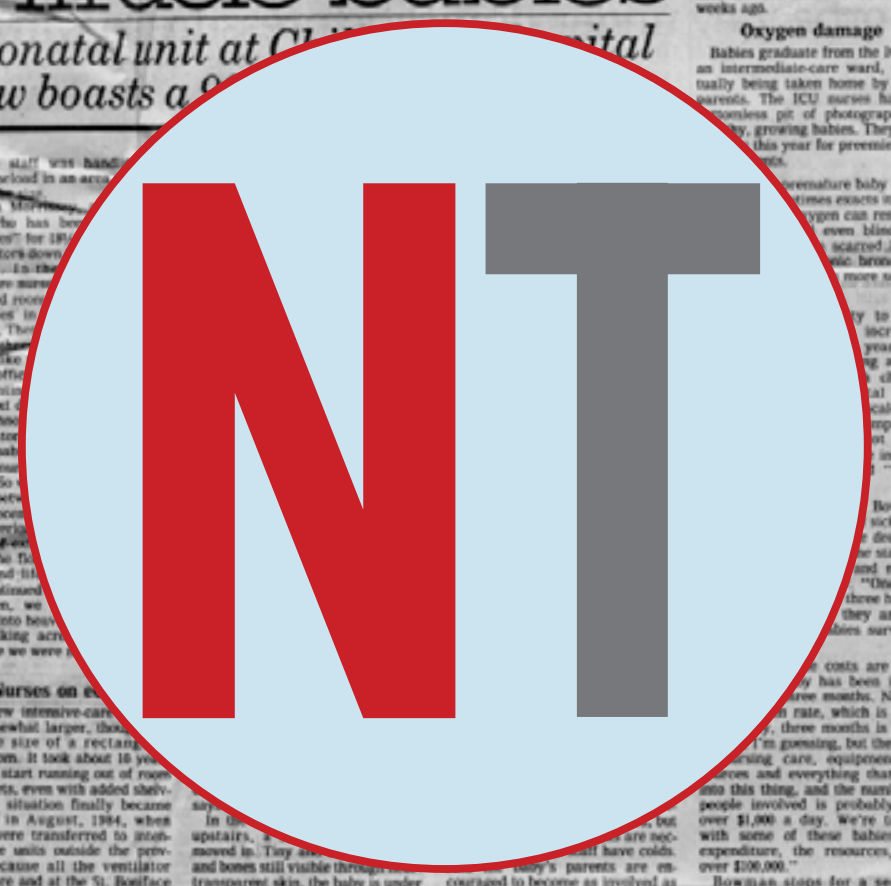

Sign up for free membership at 99nicu, the Internet community for professionals in neonatal medicine. Discussion Forums, Image Library, Virtual NICU, and more..."

\section{www.99nicu.org}

